\title{
Greek students' attitudes, perception and knowledge regarding generic medicines in times of economic crisis: a cross-sectional study
}

Philippe J. Domeyer ${ }^{1}$, Vasiliki Katsari ${ }^{1}$, Pavlos Sarafis ${ }^{2^{*}}$, Vassilis Aletras $^{3}$ and Dimitris Niakas ${ }^{1,4}$

\begin{abstract}
Background: The penetration of generic medicines in the pharmaceutical market is influenced, among others, by the consumer's attitude upon them. The attitude of students in health management and recent alumni is particularly important, as they constitute tomorrow's policymakers. The aim of our study was to assess their attitude, perception and knowledge towards generic medicines.

Methods: A cross-sectional study was undertaken, involving students in Health Management and recent alumni. The ATtitude TOwards GENerics (ATTOGEN) validated questionnaire was used, which consists of 18 items, yielding 6 scales (trust, state audit, knowledge, drug quality, drug substitution and fiscal impact), with all item responses expressed on a 5-point Likert scale and higher scores denoting greater disagreement. Correlation coefficients were computed and independent sample tests were performed using non-parametrical statistical methods.

Results: A total of 1402 students were interviewed, with a female predominance (62.88\%). The mean (SD) scores for the six scales of the ATTOGEN questionnaire were: Trust: 2.877 (0.940), State audit: 3.251 (0.967), Knowledge: 1.537 (0.688), Drug quality: 2.708 (0.971), Drug substitution: 3.828 (1.127) and Fiscal impact: 2.299 (0.860). Trust over generics was statistically significantly associated with all ATTOGEN scales (all $p<0.001$ ). In addition, the increased level of knowledge about generics was associated with recognition of the generic medicines' quality equivalence $(p<0.001)$ and positive fiscal impact $(p=0.018)$. Pharmacists declared having a superior knowledge of generic medicines, being more satisfied with the information they receive about them and strongly believing in drug substitution $(p<0.001)$. Comparatively to other professionals, pharmacists also indicated substantial differences between branded and generic medicines more often $(p<0.001)$. They also argued to a greater extent that generic medicines were invented and promoted to resolve the financial crisis of social security institutions at the expense of citizens $(p<0.001)$.

Conclusions: This study demonstrated a mixed attitude of students regarding generic medicines. Trust and knowledge emerged as key factors shaping the students' attitude towards generics. Among students, pharmacists exhibited a distinct response pattern. This study underlines the importance of addressing and correcting health management students' misbeliefs about generics' quality and utility.
\end{abstract}

Keywords: Generics, Attitude, Knowledge, Students, Greece, Drug substitution, Trust in generics, Fiscal impact, State audit, Quality of generics

\footnotetext{
* Correspondence: pavlos.sarafis@cut.ac.cy

${ }^{2}$ Nursing Department, Cyprus University of Technology, Limassol, Cyprus

Full list of author information is available at the end of the article
}

(c) The Author(s). 2018 Open Access This article is distributed under the terms of the Creative Commons Attribution 4.0 International License (http://creativecommons.org/licenses/by/4.0/), which permits unrestricted use, distribution, and reproduction in any medium, provided you give appropriate credit to the original author(s) and the source, provide a link to the Creative Commons license, and indicate if changes were made. The Creative Commons Public Domain Dedication waiver (http://creativecommons.org/publicdomain/zero/1.0/) applies to the data made available in this article, unless otherwise stated. 


\section{Background}

Generic medicines are manufactured by companies other than the manufacturer of the originator medicine, after various kinds of commercial protections granted to the latter have expired. According to the World Health Organization, generic medicines hold the following three characteristics: i) they are intended to be interchangeable with an innovator product, ii) they are manufactured without license from the innovator company and iii) they are marketed after the expiration date of the patent or other exclusive rights [1]. Generic medicines differ from biosimilars in terms of size, complexity of the active substance and the manufacturing process [2]. In order to penetrate the pharmaceutical market, they are competitively priced against their brand name counterparts, while ensuring bioequivalence. Generic medicines thus seem to be a cost-effective solution for healthcare systems, especially in light of the severe economic crisis, as their reduced cost can decrease private and public drug expenditure and can contribute to reallocation of funding towards other needs [3].

Despite the obvious cost-effectiveness of generic medicines, their penetration in the pharmaceutical market is often limited. Greece, albeit a country under severe economic surveillance, performs poorly in terms of generic medicines penetration. Strikingly, the rate of penetration 12 months after the loss of exclusivity in Greece is the lowest among the former 12-European Union member states (33\%). Even worse, the degree of generic penetration measured by the share of generic volume in total volume at 24 months after the loss of exclusivity is again the lowest in Greece (9.1\%), suggesting an important time delay to generic entry [4]. In addition, in 2015 the volume share of generics in the total Greek pharmaceutical market reached less than half the OECD27 average value (24\% vs $52 \%$, respectively) [5].

This apparently limited penetration of generic medicines may be highly influenced by a number of factors, mainly institutional ones. In particular, the effectiveness of policies implementing generic use may depend on whether physicians or patients may overrule generic substitution, the motivation or obstacles for pharmacists to dispense generic over branded products and the price difference between brand name and generic products [4]. Another recognized influential factor is the consumers' attitude, perception and knowledge towards generic medicines, which may in turn be influenced, among others, by advertising campaigns and information dissipated from the mass media [6] as well as consumers' inherent beliefs. Indeed, both healthcare providers and patients face generic medicines with skepticism [7]. Generics are thought to be inferior medicines [8], although no such tangible proof exists [9], perhaps because people often perceive "generic" to be identical to "cheap", thus indicating inferior quality
[8], although this is not always true [10]. In fact, in a study involving students, it was shown that patients complain about reduced effectiveness and increased medicationrelated side-effects when drug substitution from branded to generics occurs, which may partially be due to a loss of associated placebo effects and enhanced nocebo effects [11]. Nevertheless, patients with higher confidence in the healthcare system and higher educational and socioeconomic background seem to show less concern about generic substitution [12, 13].

In order to boost the use of generic medicines, healthcare policy makers should update their strategy. As a result, educational activities regarding the benefits of generics use should be targeted towards students of M.Sc. programs in Health Management, who are the future policymakers. Although a considerable number of studies have been published regarding healthcare students' knowledge, attitudes and perceptions concerning generic medicines [14-24], none of them used a validated tool and none has emphasized on students and alumni of M.Sc. programs of Healthcare Management. The present study attempts to fill this important gap in the literature.

\section{Methods}

\section{Study design, population and sampling}

The study sample of this cross-sectional study consisted of Greek students and recent (up to one year from graduation) alumni of the M.Sc. program in Health Management of the Hellenic Open University (H.O.U.). This program requires students to successfully complete 4 modules plus a thesis project. The choice of this particular M.Sc. program was dictated by the following facts:

1) The H.O.U. ranks first in the number of students in Greece. Therefore, the large pool of students and alumni would ensure increased statistical power.

2) Distant learning and e-learning enables the recruitment of students from a broad range of the Greek population, encompassing different age, economic and sociodemographic groups, therefore increasing the generalizability of the study's results.

3) The familiarity of all participants with electronic media enabled the use of an electronic platform for fast and flawless completion of the questionnaire.

\section{Study tool}

For the purposes of our study the ATtitude TOwards GENerics (ATTOGEN) questionnaire, an already validated instrument published elsewhere [23] was used, exploring respondents' attitudes towards generic medicines. This instrument consists of 18 items, with all item responses expressed on a 5 -point Likert scale $(1=$ totally agree, $2=$ partially agree, $3=$ neither agree nor disagree, $4=$ partially disagree, $5=$ totally disagree). During the validation 
procedure 6 scales were created, accounting for $96.1 \%$ of the total variance: Scale 1 ("Trust", 4 items), with lower values denoting increased mistrust to generic medicines; Scale 2 ("Drug quality", 3 items), with lower values supporting same drug quality of generic and brand name medicines; Scale 3 ("State audit", 3 items), with lower values indicating increased confidence that Greek and European authorities may detect irregularities in generic medicines production; Scale 4 ("Fiscal impact", 3 items), with lower values representing a stronger belief in generic medicines' positive economic impact; Scale 5 ("Knowledge", 3 items), with lower values reflecting increased knowledge regarding generic medicines; Scale 6 ("Drug substitution", 2 items), with lower values designating a more positive view towards allowing not only doctors but also pharmacists to perform substitution of brand-name with generic medicines. The instrument's internal consistency has been shown to be high (0.871); the same applies for most of its subscales [23]. The instrument's confirmatory factor analysis has also shown that the proposed model provided a good fit $($ RMSEA $=0.050, \mathrm{RMSR}=0.048, \mathrm{TLI}=0.948, \mathrm{CFI}=$ 0.960) [23]. A separate analysis was performed on questions regarding the use of generic medicines that were included in the original but not in the final version of the instrument [23].

\section{Data collection method}

Details regarding the instrument administration and ethics have already been described [24]. In brief, the instrument was uploaded to Google Drive (Google Inc., California, USA) and a web link was sent to all participants. To submit the questionnaire, they had to complete all fields. Monthly reminders were sent to maximize the response rate. Anonymity was ensured and ethics approval was obtained by the Institutional Review Board.

\section{Data analysis method}

Normality of data was tested using Kolmogorov-Smirnov test. To analyze group differences, non-parametric tests were used, including the chi-square test, when associations between two categorical values were tested, as well as the Wilcoxon rank-sum test and the Kruskal-Wallis rank test, when two or more than two related samples where compared, respectively. Spearman's correlation coefficient was used to evaluate the monotonic relationship between continuous or ordinal variables. Two-tailed $p$ values $<0.05$ were considered statistically significant. When multiple $(\mathrm{k})$ comparisons were performed, the Bonferroni correction was adopted, thereby lowering the threshold for statistical significance to $0.05 / \mathrm{k}$. Statistical analysis was performed using Stata version 13.1 (Stata Corp., Texas, USA).

\section{Results}

Among 1402 students that were contacted, 986 completed the online survey (response rate $=70.32 \%$ ). The mean age was 39.8 (7.11 years, with a female predominance (62.88\%). The majority of the students were married (63.69\%). Most of them were health professionals (80.93\%), among which $33.83 \%$ where doctors, $24.31 \%$ were nurses, $4.51 \%$ were pharmacists, $4.01 \%$ were dentists and $33.34 \%$ were other health professionals. Finally, only $4.87 \%$ were unemployed. The mean (SD) scores for the six scales of the ATTOGEN questionnaire were: scale 1 (Trust): 2.877 (0.940), scale 2 (State audit): 3.251 (0.967), scale 3 (Knowledge): 1.537 (0.688), scale 4 (Drug quality): 2.708 (0.971), scale 5 (Drug substitution): 3.828 (1.127) and scale 6 (Fiscal impact): 2.299 (0.860). Table 1 presents the descriptive statistics of items that were used in the original but not in the final version of the ATTOGEN questionnaire and where consequently not included in any of the above scales.

Inter-scale correlations of the ATTOGEN questionnaire are shown in Table 2.

The "Trust" scale was statistically significantly associated with all other ATTOGEN scales, indicating that a higher trust score (i.e. increased trust over the generics) was related to increased belief in the state's audits abilities to control generics production, in generics drug quality and positive fiscal impact, in drug substitution and an increased knowledge regarding generics (all $p<0.001$ ). In addition, students more knowledgeable about generics seemed to recognize the generic medicines' quality equivalence $($ rho $=0.361, p<0.001)$ and positive fiscal impact (rho $=$ $0.075, p=0.018$ ). The perception of the fiscal impact of generic medicines was statistically significantly associated with the rest of the ATTOGEN questionnaire scales (all $p<0.001$ ).

Inter-item associations for items I-V included only in the original version of the ATTOGEN questionnaire were strongly statistically significant in most cases (Table 3).

In particular, satisfaction with generic medicines seemed to be strongly correlated with decreased skepticism about them, increased trust on those manufactured in Greece and a weaker belief that they were invented and promoted to resolve the financial crisis of social security institutions at the expense of citizens (all $p<0.001$ ). In addition, this latter belief was associated with skepticism about generic medicines because of their lower price and with having noted substantial differences between brand-name and generic medicines (all $p<0.001$ ). Furthermore, students who declared knowing if their medications involved generic medicines (item VI) were also more likely to report: i) higher satisfaction with the information they have regarding generic medicines (item I, $p<0.001$ ), ii) substantial differences between brand-name and generic medicines (item II, $p<0.001$ ), iii) more skepticism about generic medicines because of their lower price (item III, 
Table 1 Descriptive statistics of items included in the original version of the ATTOGEN questionnaire only

\begin{tabular}{|c|c|c|c|}
\hline Item & Item description (ordinal variables) & Mean (SD) score & Median score $(\mathrm{IQR})^{\mathrm{a}}$ \\
\hline । & "I am satisfied with the information I have regarding generic medicines" & $2.781(1.369)$ & $3(2)$ \\
\hline$\|$ & "I have noted substantial differences between brand-name and generic medicines" & $3.164(1.107)$ & $3(1)$ \\
\hline III & "I am skeptical about generic medicines because of their lower price" & $3.647(1.074)$ & $4(1)$ \\
\hline IV & $\begin{array}{l}\text { "I believe that generics were invented and promoted in order to resolve the } \\
\text { financial crisis of social security institutions at the expense of citizens" }\end{array}$ & $3.267(1.251)$ & $3(2)$ \\
\hline \multirow[t]{2}{*}{ V } & $\begin{array}{l}\text { "Among two generic medicines, I would trust more the one that is } \\
\text { manufactured in Greece" }\end{array}$ & $2.216(0.967)$ & $2(2)$ \\
\hline & Item description (categorical variables) & N (\%) & \\
\hline \multirow[t]{4}{*}{$\mathrm{VI}$} & "I know if my current medications include generic medicines" & & \\
\hline & Yes & $375(38.03 \%)$ & \\
\hline & No & $24(2.43 \%)$ & \\
\hline & I am not taking medications at the moment & $587(59.53 \%)$ & \\
\hline
\end{tabular}

${ }^{\mathrm{a}} / Q R$ Interquartile range

$p=0.001)$ and iv) a better knowledge about generic medicines (scale $3, p<0.001$ ).

Most item-scale associations between items I-IV and scales 1 to 6 were also strongly statistically significant (Table 4), indicating that the satisfaction regarding generics, the notice of differences between brand-name and generics, the skepticism about generics because of their lower price and the belief that generics were invented and promoted in order to resolve the financial crisis of social security institutions are key elements related to the ATTOGEN scales.

Table 5 presents the statistically significant associations between sociodemographic factors and the questionnaire's scales. [Table 5] In addition, older students, men and pharmacists expressed a stronger preference to generic medicines manufactured in Greece (rho $=-0.144$, all $p<0.001)$ and seemed more satisfied with the information they have regarding generic medicines ( $r h o=-0.145$, all $p<0.001)$. Furthermore, compared to other professionals, pharmacists noticed substantial differences between brand name and generic medicines and believed that generics were invented and promoted to resolve the financial crisis of social security institutions at the expense of citizens, despite their better score on the "knowledge" scale; differences with other professionals were all statistically

Table 2 Inter-scale correlations ${ }^{a}$

\begin{tabular}{lllllll}
\hline Scale & 1 & 2 & 3 & 4 & 5 & 6 \\
\hline 1 (Trust) & - & & & & & \\
2 (State audit) & $-0.276^{\S}$ & - & & & & \\
3 (Knowledge) & $-0.262^{\S}$ & 0.032 & - & & & \\
4 (D quality) & $-0.620^{\S}$ & $0.361^{\S}$ & $0.352^{\S}$ & - & & \\
5 (Drug substitution) & $-0.232^{\S}$ & $0.034^{\S}$ & 0.172 & $0.208^{\S}$ & - & \\
6 (Fiscal impact) & $-0.376^{\S}$ & $0.075^{\S}$ & $0.371^{\natural}$ & $0.433^{\S}$ & $0.235^{\S}$ & -
\end{tabular}

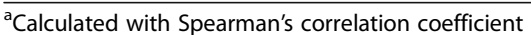

$\S p<0.001$, ๆ $p=0.018$ significant (all $p<0.001$ ). This last opinion was also expressed more favorably by women $(p<0.001)$, whose negative opinion regarding generic medicines, compared to men, was further intensified by the fact that they appeared more skeptical about generic medicines because of their lower price $(p<0.001)$. Finally, among students on medications, older students and health scientists seemed to have a better knowledge if their current medications involved generic medicines $(p=0.014$ and $<0.001$, respectively).

\section{Discussion}

This cross-sectional study, carried out on students of the M.Sc. program in Health Management of the Hellenic Open University, aimed to assess their attitude, perception and knowledge regarding generic medications, using the ATTOGEN questionnaire. This is the first study to be conducted on a large number of students while using a validated questionnaire. The results indicate a mixed overall attitude of students towards generic medicines. Indeed, they did not feel quite trustful in generic medicines or in the abilities of Greek and EU authorities to address the increased pharmacovigilance mandates that generic substitution requires. Similarly, they were not convinced about the quality equivalence of generic and brand name medicines. On the contrary, they recognized the generic

Table 3 Inter-item correlations for items I-V*

\begin{tabular}{|c|c|c|c|c|c|}
\hline Items & 1 & $\|$ & III & IV & V \\
\hline I & - & & & & \\
\hline$\|$ & 0.059 & - & & & \\
\hline III & $-0.227^{\S}$ & $0.149^{\S}$ & - & & \\
\hline IV & $-0.265^{\S}$ & $0.202^{\S}$ & $0.474^{\S}$ & - & \\
\hline V & $0.186^{\S}$ & 0.016 & -0.056 & -0.029 & - \\
\hline
\end{tabular}


Table 4 Item-scale correlations for items I-V and scales 1-6*

\begin{tabular}{lllllll}
\hline Items/scales & 1 & 2 & 3 & 4 & 5 & 6 \\
\hline I & $-0.193^{\S}$ & $0.132^{\S}$ & $0.441^{\S}$ & $0.317^{\S}$ & 0.028 & $0.084^{\S}$ \\
II & $0.434^{\S}$ & $-0.110 \S$ & 0.040 & $-0.310^{\S}$ & $-0.148^{\S}$ & $-0.241^{\S}$ \\
III & $0.512^{\S}$ & $-0.085^{\natural}$ & $-0.334^{\S}$ & $-0.323^{\S}$ & $-0.102^{\S}$ & $-0.115 \S$ \\
IV & $0.525^{\S}$ & -0.093 & $-0.320^{\S}$ & $-0.367^{\S}$ & $-0.113 \S$ & $-0.121 \S$ \\
V & -0.011 & 0.041 & $0.198^{\S}$ & 0.017 & -0.060 & -0.035 \\
\hline
\end{tabular}

* Calculated with Spearman's correlation coefficient, $\S p<0.001$, १ $p<0.01$

medicines' positive fiscal impact to some extent. They also declared an increased level of knowledge and marked disagreement with drug substitution done by pharmacists. Other Greek studies involving physicians that were conducted before $[25,26]$ and after [27] the advent of the economic crisis confirmed these findings.

Further commenting on the results of this study, knowledge emerged as a powerful factor shaping the students' attitude towards generics. Indeed, it seems rational to infer that high levels of information regarding generic medicines results in better knowledge about generics. This in turn leads students to increase their level of trust upon them and dissolve their skepticism, to recognize the quality equivalence of generics to branded products as well as their contribution to the reduction of healthcare costs and to the reallocation of resources and, therefore, to support drug substitution not only by doctors but also by pharmacists. Trust upon generics has been consistently reported as an important barrier to the increased use of generics [13]. Indeed, in this study, trust seemed to be highly correlated with all other ATTOGEN scales. In contrast, less informed students, students who were more skeptical towards generic medicines because of their lower quality or price felt that generic medicines were invented and promoted to resolve the financial crisis of social security institutions at the expense of citizens and did not acknowledge their positive fiscal impact to such an extent, compared to other students. The latter strong correlation has been confirmed by an older study on primary care patients [28]. Therefore, the myth that lower drug price equates to lower quality needs to be broken [29]. This study further suggests that students who believe in the state's audit capabilities seem more reassured about the generic medicines' quality, tend to feel less skeptical about them and to favor drug substitution not by only doctors but also by pharmacists.

Another important finding of this study is the distinct response pattern exhibited by pharmacists, compared to other professionals, which has never been studied to such an extent in the literature so far. In particular, pharmacists seemed to declare having a superior knowledge of generic medicines, to be more satisfied with the information they receive regarding this issue and to strongly believe in drug substitution, which is probably due to their superior knowledge in pharmacology. Strikingly, however, although this superiority would not justify any noticeable distinction between branded and generic medicines, comparatively to other professionals, pharmacists seemed to declare more often that they notice substantial differences between these two categories. Most importantly, despite their dual pharmaceutical and managerial academic background, they further argued more often than others that generics were invented and promoted in order to resolve the financial crisis of social security institutions at the expense of citizens. However, there seemed to be no statistically significant association between the "drug quality" or "trust" scale and profession, thus rejecting the existence of a true profession-dependent belief in inferiority of generics. This is consistent with a Czech study, where the vast majority of pharmacists stated that generic medicines are not inferior in terms of quality and side effects (83.9 and $88.8 \%$ respectively) [30]. In contrast, in another study evaluating New Zealand's pharmacists' view, knowledge and perceptions regarding generic medicines, Babar et al. conclude that, although pharmacists recognized the economic benefits of generic medicines in favor of the health system, concerns were raised regarding their quality, safety and effectiveness [31]. This is confirmed by the findings of an earlier Australian study on senior medical students and pharmacy pre-registrants [14].

Finally, the belief in generic medicines' positive fiscal impact was not consistent in all respondents' subgroups. Interestingly, doctors and pharmacists favor this opinion to a lesser extent, perhaps because of their knowledge that the price differences between originators and generics are still small in Greece [32] and that cases of high cost generic medicines exist [33].

This study bears certain limitations that should be addressed. Firstly, the study was conducted on students of the H.O.U. that may not be representative of the entire student population. On the other hand, these students belong to various age, economic and sociodemographic groups, because of the nature of the study environment (distance learning), which may somewhat increase the generalizability of the study's results. Secondly, in this sample almost all students were employed, most of which in clinical practice as healthcare providers. This high employment rate is probably due to the distinct nature of the H.O.U. studies and perhaps, to the relatively high tuition fees for Greek standards. Although employment status was only associated with the "drug quality" scale, the magnitude of associations with other scales and their level of statistical significance may have been different among other student population samples. Finally, since the data collection form was filled online, we could not guarantee that some participants might have referred to any information sources to provide the correct answer, which could have underestimated the true lack of knowledge regarding generic medicines. 
Table 5 Statistically significant associations between sociodemographic factors and the questionnaire's scales

\begin{tabular}{|c|c|c|c|c|c|}
\hline Scales & Associated factors & Mean $(S D)^{*}$ & Median $(\mathrm{IQR}) * *$ & Spearman's rhot & $p$ \\
\hline \multirow[t]{11}{*}{ State audit } & Sex & & & --- & $<0.001^{9}$ \\
\hline & Male & $3.397(0.977)$ & $3.333(1.333)$ & & \\
\hline & Female & 3.164 & 3.000 & & \\
\hline & Profession & $(0.952)$ & $(1.667)$ & --- & $<0.001^{\S}$ \\
\hline & Doctor & $3.455(1.045)$ & $3.667(1.667)$ & & \\
\hline & Dentist & $3.406(1.029)$ & $3.667(1.333)$ & & \\
\hline & Pharmacist & $3.380(1.008)$ & $3.500(1.333)$ & & \\
\hline & Nurse & $2.991(0.923)$ & $3.000(1.333)$ & & \\
\hline & Other health professional & $3.214(0.931)$ & $3.333(1.333)$ & & \\
\hline & Other profession & $3.225(0.864)$ & $3.333(1.333)$ & & \\
\hline & Units completed & --- & --- & 0.076 & $(0.018)^{\neq}$ \\
\hline \multirow[t]{11}{*}{ Knowledge } & Sex & & & --- & $<0.001^{\natural}$ \\
\hline & Male & $1.348(0.581)$ & $1.000(0.667)$ & & \\
\hline & Female & $1.648(0.722)$ & $1.333(1.000)$ & & \\
\hline & Profession & & & --- & $<0.001^{\mathrm{s}}$ \\
\hline & Doctor & $1.231(0.441)$ & $1.000(0.333)$ & & \\
\hline & Dentist & $1.188(0.359)$ & $1.000(0.167)$ & & \\
\hline & Pharmacist & $1.019(0.077)$ & $1.000(0.000)$ & & \\
\hline & Nurse & $1.524(0.579)$ & $1.333(1.000)$ & & \\
\hline & Other health professional & $1.700(0.734)$ & $1.667(1.000)$ & & \\
\hline & Other profession & $1.918(0.831)$ & $2.000(0.667)$ & & \\
\hline & Units completed & --- & -- & -0.140 & $<0.001$ \\
\hline \multirow[t]{4}{*}{ Drug quality } & Age & --- & --- & -0.064 & $(0.046)$ \\
\hline & Professional status & & & --- & $(0.039)^{n}$ \\
\hline & Employed & $2.693(0.965)$ & $2.667(1.333)$ & & \\
\hline & Unemployed & $2.986(1.047)$ & $3.167(1.667)$ & & \\
\hline \multirow[t]{16}{*}{ Drug substitution } & Age & --- & --- & 0.099 & 0.002 \\
\hline & Sex & & & --- & $(0.048)^{n}$ \\
\hline & Male & $3.872(1.209)$ & $4.000(2.000)$ & & \\
\hline & Female & $3.802(1.076)$ & $4.000(2.000)$ & & \\
\hline & Marrital status & & & --- & $(0.048)^{\S}$ \\
\hline & Single & $3.685(1.185)$ & $4.000(2.000)$ & & \\
\hline & Married & $3.889(1.096)$ & $4.000(2.000)$ & & \\
\hline & Divorced & $4.012(1.056)$ & $4.500(1.500)$ & & \\
\hline & Widowed & $3.333(1.155)$ & $4.000(2.000)$ & & \\
\hline & Profession & & & --- & $<0.001^{\S}$ \\
\hline & Doctor & $4.343(0.913)$ & $5.000(1.000)$ & & \\
\hline & Dentist & $3.969(1.177)$ & $4.250(1.500)$ & & \\
\hline & Pharmacist & $2.139(1.382)$ & $1.500(2.000)$ & & \\
\hline & Nurse & $3.644(1.101)$ & $4.000(1.500)$ & & \\
\hline & Other health professional & $3.682(1.117)$ & $4.000(1.500)$ & & \\
\hline & Other profession & $3.782(0.940)$ & $4.000(1.500)$ & & \\
\hline \multirow[t]{2}{*}{ Fiscal impact } & Profession & & & --- & $<0.001^{\S}$ \\
\hline & Doctor & $2.622(0.873)$ & $2.667(1.333)$ & & \\
\hline
\end{tabular}


Table 5 Statistically significant associations between sociodemographic factors and the questionnaire's scales (Continued)

\begin{tabular}{|c|c|c|c|c|c|}
\hline Scales & Associated factors & Mean $(\mathrm{SD})^{*}$ & Median $(\mathrm{IQR}) * *$ & Spearman's rhot & $p$ \\
\hline & Dentist & $2.427(0.963)$ & $2.000(1.000)$ & & \\
\hline & Pharmacist & $2.611(1.006)$ & $2.667(1.500)$ & & \\
\hline & Nurse & $2.103(0.798)$ & $2.000(1.000)$ & & \\
\hline & Other health professional & $2.159(0.812)$ & $2.000(1.000)$ & & \\
\hline & Other profession & $2.151(0.773)$ & $2.000(1.000)$ & & \\
\hline
\end{tabular}

* for categorical variables, ${ }^{* *} I Q R$ Interquartile rage, ffor ordinal or continuous variables, ๆ Wilcoxon rank-sum test, § Kruskal-Wallis rank test, $\neq p$-values in parentheses denote $p$-values $<0.05$ who become statistically insignificant after application of the Bonferonni correction (corrected $p$-value $=0.007$ )

\section{Conclusions}

This study demonstrated a mixed attitude of students regarding generic medicines. Knowledge emerged as an important factor shaping the students' attitude towards generics. Among students, pharmacists exhibited a distinct response pattern. This study further stresses the need to address and correct health management students' misconceptions and myths related to generics' quality and utility. It is important that policymakers empower health professionals with detailed information about generic medicines, in order to ascertain the steady growth of their market position in the near future. Further studies are needed to confirm our findings and ascertain their generalizability to the entire Greek population.

\section{Additional file}

Additional file 1: Dataset. (XLSX $304 \mathrm{~kb})$

\section{Abbreviations}

ATTOGEN: ATtitude TOwards GENerics; HOU: Hellenic Open University

\section{Acknowledgements}

None.

\section{Funding}

None to report.

\section{Availability of data and materials}

All data generated or analysed during this study are included in this published article [Additional file 1].

\section{Authors' contributions}

PJD conducted the data analysis and wrote the manuscript. VK acquired and interpreted the data. PS assisted in the interpretation of the data and made significant revisions to the manuscript. VA assisted in data analysis and critically revised the manuscript for important intellectual content. DN designed and supervised the study and critically revised the manuscript for important intellectual content. All authors read and approved the final manuscript.

\section{Ethics approval and consent to participate}

Approval of the study by the Review Board of the Hellenic Open University was obtained. All participants provided their written informed consent to participate in the study and were reassured that their anonymity would be respected.

\section{Consent for publication}

Not applicable.
Competing interests

The authors declare that they have no competing interests.

\section{Publisher's Note}

Springer Nature remains neutral with regard to jurisdictional claims in published maps and institutional affiliations.

\section{Author details}

${ }^{1}$ School of Social Sciences, Hellenic Open University, Patras, Greece. ${ }^{2}$ Nursing Department, Cyprus University of Technology, Limassol, Cyprus. ${ }^{3}$ Department of Business Administration, University of Macedonia, Thessaloniki, Greece. ${ }^{4}$ Medical School, National and Kapodistrian University of Athens, Athens, Greece.

Received: 6 March 2018 Accepted: 2 November 2018

Published online: 15 November 2018

\section{References}

1. Shargel L, Kanfer I, editors. Generic drug product development. Boca Raton: CRC Press; 2013

2. Misra A. Are biosimilars really generics? Expert Opin Biol Ther. 2010;10(4): 489-94.

3. Perry G. The European pharmaceutical market in review: 2006 and beyond. Journal Gen Med. 2006;4:4-14.

4. Kanavos P. Measuring performance in off-patent drug markets: a methodological framework and empirical evidence from twelve EU member states. Health Policy. 2014;118:229-41.

5. OECD. Health at a Glance 2017: OECD Indicators. Paris: OECD Publishing; 2017. https://doi.org/10.1787/health_glance-2017-en

6. Babar ZU, Kan SW, Scahill S. Interventions promoting the acceptance and uptake of generic medicines: a narrative review of the literature. Health Policy. 2014:117(3):285-96.

7. Meredith PA. Bioequivalence and other unresolved issues in generic drug substitution. Clin Ther. 2003;25(11):2875-90.

8. PHARMAC Consumer Advisory Committee. Minutes of the PHARMAC Consumer Advisory Committee (CAC) Meeting: Friday 13 July 2007. Wellington: PHARMAC; 2007.

9. Kopp C, Badiane C. Generics: keep a balanced view. Prescrire Int. 2014 23(146):52-5.

10. Heikkilä R, Mäntyselkä $P$, Ahonen R. Do people regard cheaper medicines effective? Population survey on public opinion of generic substitution in Finland. Pharmacoepidemiol Drug Saf. 2011;20(2):185-91.

11. Faasee K, Cundy T, Gamble G, Petrie K. The effect of an apparent change to a branded or generic medication on drug effectiveness and side effects. Psychosom Med. 2013;75:90-6.

12. Rathe J, Søndergaard J, Jarbøl DE, Hallas J, Andersen M. Patients' concern about their medicine after a generic switch: a combined cross-sectional questionnaire and register study. Pharmacoepidemiol Drug Saf. 2014;23(9): 965-73.

13. Dunne SS. What do users of generic medicines think of them? A systematic review of consumers' and patients' perceptions of, and experiences with, generic medicines. Patient. 2016;9(6):499-510.

14. Hassali MA, Kong DC, Stewart K. A comparison between senior medical students' and pharmacy pre-registrants' knowledge and perceptions of generic medicines. Med Educ. 2007;41(7):703-10. 
15. Hassali MA, Stewart K, Kong DC. A national survey on knowledge and perceptions of senior medical students in Australia about generic medicines. Med J Aust. 2008;188(2):123-4.

16. Hassali MA, Kong DC, Stewart K. Knowledge and perceptions of recent pharmacy graduates about generic medicines. Pharm Educ. 2007;7(1):89-95.

17. Siam MKS, Khan A, Khan TM. Medical and pharmacy students' knowledge and perceptions about generic medicines in Bangladesh. J Pharm Health Serv Res. 2013;4(1):57-61.

18. Jamshed SQ, Ibrahim MI, Hassali MA, Sharrad AK, Shafie AA, Babar ZU. Understanding and perceptions of final-year doctor of pharmacy students about generic medicines in Karachi, Pakistan: a quantitative insight. Adv Med Educ Pract. 2015;6:359-66

19. Othman GQ, Abdulghani MAM. Assessment of knowledge and perceptions of generic medicines among pharmacy students in Yemeni universities. Pharm Educ. 2015;15(1):93-8.

20. Othman GQ, Abdulghani MAM, AlHyi HA, Alkhazzan A, Al-Qadsi F. Knowledge and perceptions of final-year medical students in Yemeni universities about generic medicines. Yemeni J Med Sci. 2016;10:16-24.

21. Gyawali S, Hassali MA, Saha A. A survey exploring the knowledge and perceptions of senior medical students in Nepal toward generic medicines. SAGE Open Med. 2016;4:2050312116662570. https://doi.org/10.1177/ 2050312116662570 eCollection 2016.

22. Shankar PR, Herz BL, Dubey AK, Hassali MA. Assessment of knowledge and perceptions toward generic medicines among basic science undergraduate medical students at Aruba. Indian J Pharmacol. 2016;48(Suppl 1):S29-32.

23. Domeyer PJ, Aletras V, Anagnostopoulos F, Katsari V, Niakas D. Development and validation of a tool to assess knowledge and attitudes towards generic medicines among students in Greece: the ATtitude TOwards GENerics (ATTOGEN) questionnaire. PLoS One. 2017;12(11): e0188484.

24. James PB, Bah AJ, Margao EK, Hanson C, Kabba JA, Jamshed SQ. Exploring the knowledge and perception of generic medicines among final year undergraduate medical, pharmacy, and nursing students in Sierra Leone: a comparative cross-sectional approach. Pharmacy (Basel). 2018;6(1). pii: E). https://doi.org/10.3390/pharmacy6010003.

25. Tsiantou V, Zavras D, Kousoulakou H, Geitona M, Kyriopoulos J. Generic medicines: Greek physicians' perceptions and prescribing practices. J Clin Pharm Ther. 2009;34(5):547-54.

26. Theodorou M, Tsiantou V, Pavlakis A, Maniadakis N, Fragoulakis V, Pavi E, Kyriopoulos J. Factors influencing prescribing behaviour of physicians in Greece and Cyprus: results from a questionnaire based survey. BMC Health Serv Res. 2009:9:150

27. Labiris G, Fanariotis M, Kastanioti C, Alexias G, Protopapas A, Karampitsakos T, Niakas D. Greek physicians' perceptions on generic drugs in the era of austerity. Scientifica (Cairo). 2015;2015:251792. https://doi.org/10.1155/2015/ 251792.

28. Himmel W, Simmenroth-Nayda A, Niebling W, Ledig T, Jansen RD, Kochen MM, Gleiter $\mathrm{CH}$, Hummers-Pradier E. What do primary care patients think about generic drugs? Int J Clin Pharmacol Ther. 2005;43(10):472-9.

29. Kaplan WA, Ritz LS, Vitello M, Wirtz VJ. Policies to promote use of generic medicines in low and middle income countries: a review of published literature, 2000-2010. Health Policy. 2012;106(3):211-24.

30. Maly J, Dosedel M, Kubena A, Vlcek J. Analysis of pharmacists' opinions, attitudes and experiences with generic drugs and generic substitution in the Czech Republic. Acta Pol Pharm. 2013;70(5):923-31.

31. Babar ZU, Grover P, Stewart J, Hogg M, Short L, Seo HG, Rew A. Evaluating pharmacists' views, knowledge, and perception regarding generic medicines in New Zealand. Res Social Adm Pharm. 2011;7(3):294-305.

32. Vogler S. How large are the differences between originator and generic prices? Analysis of five molecules in 16 European countries. Farmeconomia Health Econ Ther Pathways. 2012;13(Suppl 3):29-41.

33. Alpern JD, Stauffer WM, Kesselheim AS. High-cost generic drugs-implications for patients and policymakers. N Engl J Med. 2014;371(20): 1859-62.

Ready to submit your research? Choose BMC and benefit from:

- fast, convenient online submission

- thorough peer review by experienced researchers in your field

- rapid publication on acceptance

- support for research data, including large and complex data types

- gold Open Access which fosters wider collaboration and increased citations

- maximum visibility for your research: over $100 \mathrm{M}$ website views per year

At $\mathrm{BMC}$, research is always in progress.

Learn more biomedcentral.com/submissions 